\title{
Kent Ekolojisine Farklı Bir Yaklaşım: Tozlaşma Bahçeleri
}

\section{A Different Approach to Urban Ecology: Pollinator Gardens Arzu Özdemira, Aysel Ulus ${ }^{b, *}$}

aİstanbul Üniversitesi-Cerrahpaşa, Orman Fakültesi, Peyzaj Mimarlığı Bölümü, İstanbul, 34473, Türkiye.

bDr. Öğr. Üyesi, İstanbul Üniversitesi-Cerrahpaşa, Orman Fakültesi, Peyzaj Mimarlığı Bölümü, İstanbul, 34473, Türkiye.

Article history: Received 03-12-2018 / Accepted 20-03-2019

\section{ÖZET ABSTRACT}

Doğanın dış olumsuz faktörlerle değiştirilmesinin hatta bozulmasının sonucunda, dünya üzerinde her gün yaklaşık 140 bitki ve hayvan türünün yok olduğu tahmin edilmektedir. Günümüzde kent içerisindeki arazi kullanımında sürekli yaşanan değişim ve kent yakın çevresindeki alanlardaki yoğun tarım faaliyetler nedeniyle, doğal ve yarı doğal habitatlarda büyük kayıplar meydana gelmektedir. Tozlaşma bahçeleri, özellikle kentsel alanlarda azalan tozlaştırıcı nüfusunun dengelenmesi ve kent içi biyoçeşitliliğin desteklenmes açısından önem taşımaktadır. Araştırma, tozlaşma bahçelerinin tesisinde dikkat edilmesi gereken unsurların ortaya konulması ve yurt dışında bu bahçelerde yoğun olarak kullanılan bitki türleri içerisinden, İstanbul şartlarında doğal olarak yetişen türlerin tespit edilmesine yöneliktir. Çalışmada, İstanbul koşullarında doğal olarak yetişen ve tozlaşma bahçelerinde kullanım potansiyel bulunan 27 cinse ait 137 bitki türü tespit edilmiştir. Çalışma sonucunda bu bahçelerin, farklı kentse ortamlarda tesis edilebileceği ve pek çok bahçe tipi ile ilişkili şekilde düzenlenebileceği belirtilmiştir. Tespit edilen 137 türün, kaya bahçeleri, koku bahçeleri, çatı ve teras bahçeleri gibi farklı bahçe tiplerinde kullanılması ile bu bahçelerin potansiyel tozlaşma bahçelerine dönüştürülmesine dair öneriler getirilmiştir.
An estimated 140 plant and animal species disappear every day in the world as a result of the alteration or even deterioration of nature by negative external factors. Nowadays, great losses occur in natural and semi-natural habitats due to the constant changes in land use in the cities and intensive agricultural activities in the vicinity of the cities. Pollinator gardens are important in order to balance the decrease of the pollinator population, especially in urban areas, and to support urban biodiversity. The study aims to identify the plant species that grow naturally in the conditions of the city of Istanbul amongst those used extensively in pollinator gardens in other countries. It further aims to reveal the elements that require attention in the process of establishing pollinator gardens. In the study, 137 plant species belonging to 27 genera, which grow naturally in İstanbul's conditions and have potential use in pollinator gardens, have been identified. As a result of the study, it is stated that gardens can be established in different urban environments and can be arranged in relation with many garden types. Together with the possible uses of those species in different types of gardens, such as rock gardens, fragrance gardens, roof and terrace gardens, suggestions are made to transform those gardens into potential pollinator gardens.

Anahtar Kelimeler: Tozlaşma, Kent Ekolojisi, Keywords: Pollination, Urban Ecology, Biodiversity, Biyoçeşitlilik, İstanbul

Istanbul

\section{GİRIŞ}

Doğada rüzgâr, su, insanlar, kuşlar, bazı memeli hayvan türleri ve böcekler tozlayıcı olarak görev yaparlar. Bu tozlayıcılar içinde en etkilileri ise hedefleri doğrudan çiçekler olması nedeniyle böceklerdir (Yılmaz, 2016; Sıralı ve Cinbirtoğlu, 2018). Çiçeklerden nektar ve polen toplayan böcekler ile böceklerle tozlaşan bitkiler arasında karşılıklı yarar ilişkisi olup, her ikisi milyonlarca yıl önce birlikte evrimleşmişlerdir (Sinnathamby ve diğ., 2013; Korkmaz, 2016). Böceklerin ve bitkilerin birlikte gelişimi, her iki grup için de 100 milyondan fazla yıldır önem taşımaktadır (Evert ve Eichborn, 2015). Ekosistem dengesinin korunması, bitkiler ve tozlaşmalarını sağlayan polinatör böcekler arasındaki ilişkinin sürdürülebilmesine bağlıdır. Bu bakımdan polinatör böcekler, küresel biyoçeşitliliğin anahtar bileşenidir (Potts ve diğ., 2010; Bağrıaçık, 2017).

Tarımı yapılan bitkilerinin \%75'i tozlaşmak için böceklere bağımlıdırlar. Yapılan çalışmalar, ürün verimi ve kalitesinin artırılmasında polinatör böceklerin önemini ortaya koymuştur (Klein ve diğ., 2007; Bağrıaçık, 2017). Başta arılar olmak üzere, böcekler tarafından gerçekleştirilen tozlaşma sonucu elde edilen ürünler, insan gıdasının yaklaşık \%35'ini oluşturmaktadır (Buchmann ve Nabhan, 1996; Sıralı ve Cinbirtoğlu, 2018). Buna göre tozlaşma gerçekleşmediği takdirde bitkisel üretimde bu oranda bir düşüş görülebileceği gerçeği söz konusudur. Bununla birlikte tozlaştırıcıların çalışması olmaksızın, birçok yerli bitkinin gelecek kuşaklar için tohum üretmesi mümkün değildir. Bu tohumlar ve sıklıkla onlara eşlik eden 
meyveler, kuşların ve birçok memeli türünün yaklaşık \%25'i için önemli besin kaynakları oluşturmaktadır (Krischik ve diğ., 2015).

Günümüzde özellikle kentsel alanlardaki tozlaştırıcı canlıların sayısında azalmalar olduğu görülmektedir. Bu azalmaların ardında pek çok neden vardır. Ancak çoğu neden, doğrudan ya da dolaylı olarak insan faaliyetleriyle ilişkilendirilebilir (Mader ve diğ., 2011; Landis ve diğ., 2014). Böcek tozlaştırıcılar, yoğun arazi kullanımı, iklim değişikliği, yabancı türler ile zararlı böceklerin ve patojenlerin yayılmasının etkileri (Şekil 1.) nedeniyle artan baskıyla karşı karşıyadır (Kearns ve diğ., 1998; Potts ve diğ., 2010; Vanbergen ve diğ., 2013). Özellikle kentsel alanlarda, parçalanmış habitatlarda tozlaştırıcıların hareket kabiliyeti azaltmakta, beslenme ve barınma imkanlarını kısıtlanmaktadır. Küresel ısınmanın bir sonucu olarak bitkilerde çiçeklenme başlangıcında ve tozlaştırıcıların ilk görünüm tarihlerinde sıcaklık artışına tepki olarak doğrusal artış olmaktadır (Hegland ve diğ, 2009; Şahin ve diğ, 2015). Bu durum tozlaştırıcıların daha az besin elde edip, daha az tozlaştırma işlemi gerçekleştirmesine neden olmaktadır.

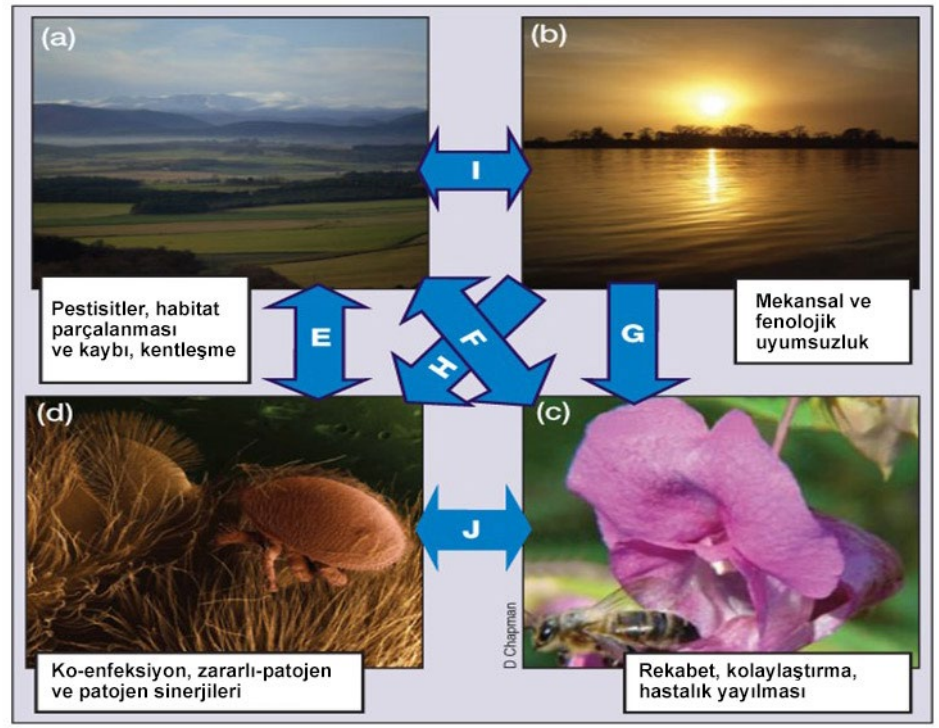

Şekil 1. Tozlaştırıcıları etkileyen, temel baskıları (paneller, a - d) ve etkileşimlerini (oklar, E - J) gösteren kavramsal çerçeve. (a) Arazi kullanımının yoğunlaşması; (b) iklim değişikliği; (c) yabancı türler; (d) zararlılar ve patojenler (bir bal arısında Varroa destructor) (Vanbergen ve diğ., 2013).

Polinatör böceklerdeki kayıplar, ekonomik olarak özellikle insan besini olan bitkilerde ticari kayıplara ve ürün kalitesinin azalmasına, ekolojik olarak ise ekosistem dengesinin bozulmasına sebep olmaktadır. Ekonomik ve ekolojik sürdürülebilirlik açısından tozlaştırıcı böcekler ekosistemlerde yeri doldurulamaz bir değere sahiptirler (Bağrıaçık, 2017). Bu durum ekosistemlerin kilit türlerinden olan tozlaştırıcı böcekleri destekleyecek yeni alanlar oluşturmanın önemini ortaya çıkarmaktadır.

Tozlaşma bahçeleri, çiçekten çiçeğe veya bazı durumlarda çiçek içerisinde polen aktarımını sağlayan, arıları, kelebekleri, güveleri, sinek kuşlarını ve diğer faydalı canlıları çeken bahçelerdir (Url-1, 2016). Bu bahçeler, tozlaştırıcıların doğal yaşam alanlarının temsili bir örneğini oluşturur. Tozlaştırıcılar ve diğer yaban hayatı için barınma, beslenme ve popülasyon artışı olanağı sağlayarak, bu canlıların olumsuz kentsel koşullarda yaşamlarını devam ettirebilmelerine katkı sağlar. Bahçeye çekilen tozlaştırıcılar, bitki türlerinin yaşamlarını devam ettirebilmesini ve çiçek ve meyve veriminin artmasını destekler.

Kentleri birer insan ekosistemi (içinde insanın yer aldığı ve insan tarafından oluşturulmuş ekosistem) olarak inceleyen kent ekolojisi araştırmaları, birçok disiplinin bakış açılarını birleştirmekte ve bütüncül bir yaklaşımı savunmaktadır. Hoyer ve Naess; kent ekolojisini "kentlerdeki aktivitelerin doğal kaynaklar ve çevre üzerindeki etkilerini araştırarak; gelecek nesilleri de düşünerek yerel ve küresel ölçekte biyolojik çeşitlilik ve yaşam kalitesini sağlayacak koşulları ortaya koyan çalışmalar" olarak tanımlamaktadır (Riepel 2006; Karadağ, 2009). Bu kapsamda tozlaşma bahçeleri kent ortamında, görsel kalitenin artırılması, biyoçeşitliliğin desteklenmesi, bitki yoğunluğunun zenginleştirilmesi ile kent içi hava kalitesinin artırılması, 
zayıflayan insan-doğa ilişkilerinin yeniden canlandırılması, gözlem ve fotoğrafçılık imkanları oluşturulması gibi işlevleri ile kent ekolojisine önemli katkılar sağlamaktadır. Bu bahçelerin kentlere konumlandırılması daha sağlıklı ve yaşanılabilir kentler oluşturulabilmesi açısından önem taşımaktadır.

Araştırmada tozlaşma bahçesi tesisinde dikkat edilmesi gereken çeşitli unsurlara yer verilmiş ve yurt dışında bu bahçelerde yoğun olarak kullanılan cinsler incelenerek kaynak bir tür listesi oluşturulmuştur. Tespit edilen türlerin habitat bilgileri değerlendirilerek koku bahçesi, kaya bahçesi, çatı ve teras bahçesi gibi çeşitli bahçe tiplerinde kullanılması ile bu bahçelerin potansiyel tozlaşma bahçelerine dönüştürülmesine dair öneriler getirilmiştir. Bu bahçelerin kent içerisinde çeşitli alanlarda oluşturulması ile tozlaştırıcılar için yaşam alanı koridorları oluşturularak geniş bir peyzajda bağlantı imkanı sağlanabileceği, biyoçeşitliliğin desteklenebileceği ve kent ekolojisine olumlu katkılar sağlanabileceği görüşüne varılmıştır.

\section{MATERYAL VE YÖNTEM}

Araştırma, yaklaşık on beş milyon nüfusa sahip ve yoğun bir kentsel gelişim ve değişim süreci yaşamış olan, İstanbul metropolü üzerinde gerçekleştirilmiştir. Bu amaçla öncelikle "tozlaşma bahçeleri" kavramı, bu kavramın kent ekolojisi açısından önemi ve tozlaşma bahçesi tesisinde dikkat edilmesi gereken unsurlar ile ilgili literatür çalışmaları yapılmıştır.

Bahçelerde kullanım potansiyeli olan bitkilerin tespitine yönelik olarak çalışmanın ikinci aşamasında; Mihail Garbuzov ve Francis L. W. Ratnieks'in, pek çok listeyi değerlendirerek oluşturdukları "The Strengths and Weaknesses of Lists of Garden Plants to Help Pollinators" (Garbuzov ve Ratnieks, 2014) araştırmasındaki bitki listesi referans olarak kullanılmıştır. Bu liste Britanya, Kuzey Amerika ve Batı Avrupa'da, amatör yazarlar, profesyoneller ve hükümetler tarafından oluşturulan 15 bitki listesi incelenerek, en çok listede ortaklık gösteren türlerin belirlenmesi ile oluşturulmuş olup tespit edilen toplam 455 cinsten, 10 veya daha fazla listede ortaklık gösteren, 38 cinsi kapsamaktadır. Türkiye Bitkileri Veri Servisi (Url-2) kullanılarak İstanbul florası içerisinden, bu "Rehber Bitki Listesi" taranmış, her iki listede ortaklık gösteren cinsler ayrı bir liste haline getirilmiştir. Bu cinslere ait yine İstanbul koşullarında doğal yetişen türler ortaya çıkarılmıştır. Bu türlerin habitatları eşliğinde kullanım yerleri (kaya bahçesi, koku bahçesi, çatı bahçesi vb.) önerileri yapılmıştır.

\section{BULGULAR}

\section{Tozlaşma Bahçelerinin Tesisinde Dikkat Edilmesi Gereken Unsurlar}

\section{- Alan Özellikleri}

Tozlaşma bahçesi tesis edilecek alanın güneş alma durumu dikkate alınmalıdır. Bütün böcek tozlaştırıcılar soğukkanlı olduğundan dolayı tozlaşma bahçeleri güneşli bir yere yerleştirilmeli ve günde en az 6-8 saat doğrudan güneş ışığı almalıdır (Landis ve diğ., 2014). Çoğu zaman sabah güneşi aldığı ve hızı bir ısınma gösterdiği için güney ve güneydoğu yönleri idealdir.

Yoğun rüzgarlı alanlar tozlaştırıcıların uçuş kabiliyetini sınırlamaktadır. Örneğin, saatte 30 kilometrenin üzerinde esen rüzgâr, arıların uçuşunu etkilemekte, çiçek ziyaretlerini adeta engellemektedir. Çiçeğin üzerinde durmakta zorlanan arı dakikada ancak 3-5 çiçek ziyaret edebilir. Polen veya balözünün taşınması da yine rüzgâr tarafından olumsuz etkilenmektedir (Url-3). Böyle alanlara konumlandırılacak bahçeler, rüzgar bariyerleri veya çitler ile kapatılmalıdır. Bitkisel çitlerin kullanılması, bahçede tozlaştırıcıların yanında başka canlılar için de korunma ve dinlenme imkanı sağlaması nedeniyle ekolojik açıdan daha uygun olacaktır.

Tozlaştırıcıların barınma ihtiyacının karşılanabilmesi için bahçede kuru dal yığınları, kütükler, ölü ağaçlar ya da tozlaştırıcı oteli olarak adlandırılan barınaklar bulundurulmalıdır (Şekil 2.). Bu barınakların bahçe içerisine konumlandırılması, tozlaştırıcılar için hem beslenme hem de yuvalama imkanını birlikte oluşturarak, bu canlıların özellikle soğuk dönemlerdeki olumsuz çevre koşullarından en az miktarda etkilenmesini sağlayacaktır. Bahçedeki bazı bitki türlerini budamadan bırakmak da barınak oluşturmak için alternatif bir yöntemdir. Aynı zamanda bu bitkilerin tohumları, kış mevsiminde kuşlar için besin kaynağı oluşturabilir. 


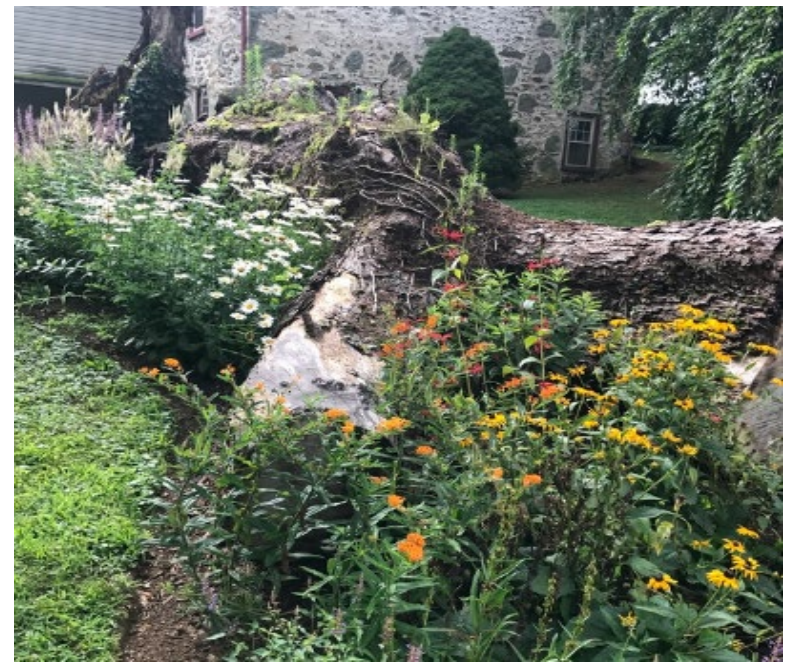

Şekil 2. Redwood Farm Tozlaşma Bahçesi (Amerika Birleşik Devletleri) (Url-4, 2017)

Tozlaşma bahçesi kurulumu için kentsel alanlarda, ev bahçeleri, toplu konut bahçeleri, parklar, okul bahçeleri, çatı ve teras bahçeleri ve benzeri alanlar tercih edilebileceği gibi yol kenarı, şev ve kavşaklar gibi farklı alanlar da tercih edilebilmektedir (Şekil 3.). Bu alanların sahip olduğu farklı çevresel koşullar ve ihtiyaçlar, bahçe oluşturma sürecinde dikkate alınmalıdır.

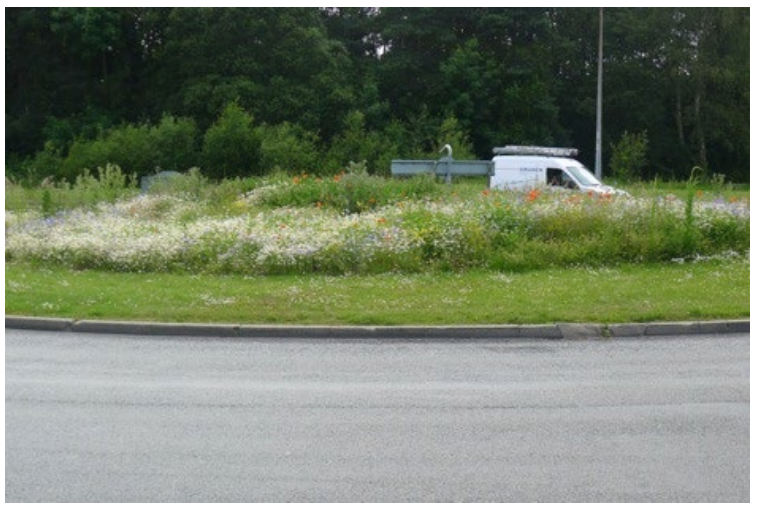

Şekil 3. Warrington Dönel Kavşağı Arı ve Tozlaştırıcı Bahçesi (İngiltere) (Url-5, 2011)

\section{- Bitki Seçimi}

Tozlaştırıcılar, yerel yetişme mevsimi, iklim ve toprak faktörlerine iyi adapte olmuş doğal bitkilerle evrimleşmiştir. Çoğu tozlaştırıcı belirli bitki türleri ile beslenir. Yeşil arılar (Agapostemon) daha çok açık yüzeyli ayçiçeklerini tercih ederken, sinek kuşları (Trochilidae) uzun, tüp şeklindeki hanımeli çiçeklerinden nektar içer (Url-6). Bölgeye özgü doğal bitkiler, iklime, toprağa ve bulundukları coğrafyaya binlerce yıl boyunca uyum sağlamış oldukları için sert iklim koşullarına, susuzluğa, hastalık ve zararlılara karşı, yerli olmayan bitkilere göre daha dirençlidir. Aynı alanda doğal olarak bulunan bitki türlerinin aynı ışı, su ve besin öğelerine ihtiyaç duyma ihtimalleri daha yüksektir. Bu nedenle, planlama yapılacak alan ve çevresindeki doğal türlere bakılarak, birlikte verimli bir şekilde büyüme gösteren ve tozlaştırıcıları çekme potansiyeli olan türlerin seçilip kullanılabilmesi mümkündür.

Yılın farklı zamanlarında farklı tozlaştırıı türleri aktiftir. Bu nedenle, mevsim boyunca sürekli bir polen ve nektar kaynağı sağlamak önemlidir (Landis ve diğ., 2014). Baharın başında ortaya çıkan çiçekler, yeni gelişen tozlaştırıcılara beslenme olanağı sağlamaktadır. Sonbahar aylarındaki çiçekler ise kışlamak isteyen tozlaştırıcıları desteklemek için önemlidir. Bu nedenle yapılacak düzenlemeler, bahçede tüm çiçeklenme dönemlerinde çiçekli bitki bulunacak şekilde planlanmalıdır.

Farklı çiçek şekilleri ve renkleri olan bitkiler, farklı tozlaştırıcıları bahçelere çekmektedir (Ellsworth, D., 2014). Bitki türlerindeki bu çeşitlilik, tozlaştırıcılara barınak ve beslenme çeşitliliği oluşturulması açısından önemlidir (Şekil 4.). Bitki türlerinin seçimi bölgede bulunan ya da bahçede görülmek istenen tozlaştırıcı türlerine göre farklılık gösterebilmektedir. Örneğin, 
özellikle kelebekler bahçeye çekilmek isteniyorsa, bölgedeki kelebek türlerinin nektar ve polen bitkilerine ağırlık veren bir düzenleme yapılabilir.

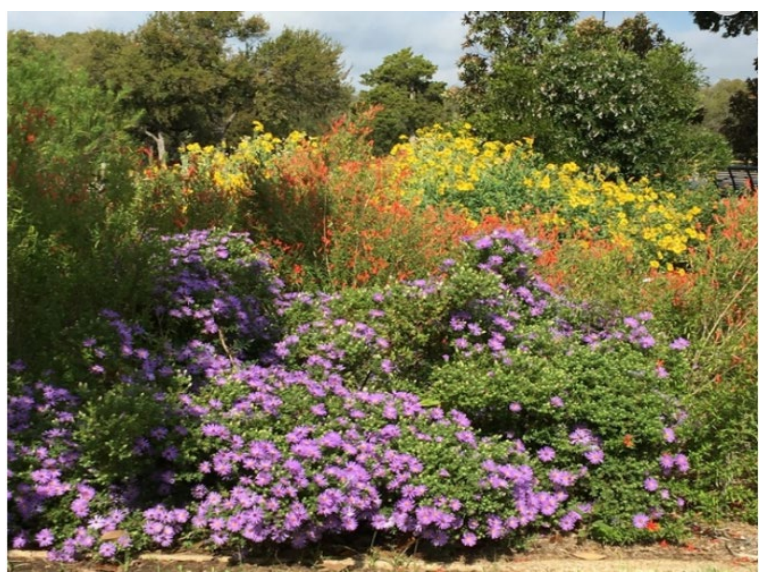

Şekil 4. Oak Cliff Parkı Kelebek ve Tozlaştırıcı Bahçesi (Amerika Birleşik Devletleri) (Url-7, 2018)

Kelebeklerin çoğunun tırtılları, beslenmek için yalnızca bir bitki cinsini kullanır. Bu bitkiler konukçu bitkiler olarak bilinir. Buna karşılık, yetişkin kelebekler yiyecek için doğal ve istilacı bitkiler gibi çok çeşitli bitkileri kullanabilir (Landis ve diğ., 2014). Bitki seçimi sırasında bölgedeki kelebek türlerinin konukçu bitkileri belirlenerek, bahçe içerisinde bu türlere de yer verilebilir. Konukçu bitkiler sayesinde bahçede, kelebeklerin yaşam döngülerini gözlemleme imkanı da oluşturulur.

\section{- Su Kaynakları}

Tüm organizmaların olduğu gibi, böcek tozlaştırıcıların da hidrasyon için suya ve aynı zamanda çözünmüş mineral kaynağına ihtiyacı vardır. Bazı tozlaştırıcılar, birkaç Osmia spp. türü gibi, larvalarını yetiştirmek için yaptıkları çamurdan yapılar için suya ihtiyaç duymaktadır (Cane ve diğ., 2007; Landis ve diğ., 2014). Tozlaştırıcıların, özellikle en aktif oldukları ilkbahar ve yaz dönemlerinde su kaynaklarına yakın olmaları önemlidir. Su kaynaklarına yakın alanlarda olmayan bahçelerde yapay su kaynakları oluşturulmalıdır. Bahçe içerisine yerleştirilecek sığ bir su kaynağı, kuş havuzu ya da çamurlu su birikintisi başta kelebekler olmak üzere pek çok tozlaştırıcıyı destekleyecektir (Şekil 5.).

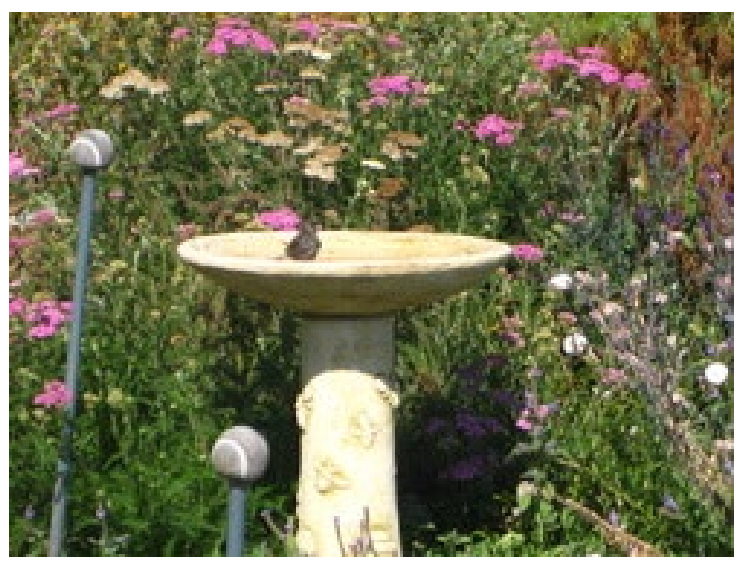

Şekil 5. Oxford Arı Bahçesi (Url-8, 2018)

\section{- İnsektisit Kullanımı}

İnsektisitler, yani böcek öldürücü kimyasallar, tozlaştırıcı böcekleri doğrudan etkilemektedir. Özellikle tarım arazilerinde, tarımsal zararlılara karşı uygulanan zirai mücadele ilaçları tozlaştırıcı böceklerin yok olmasında da etkilidir (Tirado ve diğ., 2013; Bağrıaçık, 2017). Bu ilaçların etkileri tozlaştırıcıları doğrudan öldürmek ya da davranışları, yaşam süreleri ve hastalığa yatkınlıklarını etkilemek şeklinde olabilir (Ellsworth, D., 2014). Bu nedenle tozlaşma bahçesini, insektisitler ve tozlaştırıcılar için zararlı diğer uygulamalardan korumak, kritik önem taşımaktadır. İlaçlama yerine biyolojik mücadelenin tercih edilmesi bu bağlamda önemlidir. İlaç kullanılması gereken durumlarda ise, bitkinin çiçeklenme dönemine dikkat edilmeli, 
tozlaştırıcıların daha az aktif olduğu, çiçeklenme öncesi veya sonrası dönemlerde uygulama yapılarak, tozlaştırıcıların en az zararı görmesi sağlanmalıdır.

\section{İstanbul Koşullarında Tozlaşma Bahçelerinde Kullanım Potansiyeli Olan Doğal Bitki Türleri}

İstanbul $511.000 \mathrm{~km}^{2}$ alan üzerinde yaklaşık 2500 yabani çiçekli bitki ve eğreltiye ev sahipliği yapmaktadır (Özhatay, N. ve diğ., 2010). 'The Strengths and Weaknesses of Lists of Garden Plants to Help Pollinators' araştırmasında yer alan 38 cins içerisinden, İstanbul'da doğal olarak yetişen ve tozlaşma bahçelerinde kullanım potansiyeli bulunan 27 cinse ait 137 bitki türü tespit edilmiştir. Bu sayı, 2500 bitki türünün yaklaşık \%5'lik bir kısmını oluşturmaktadır.

İstanbul'da 61 endemik bitki türü bulunmaktadır (Url-9). Bu bitkilerin 10 tanesi, tespit edilen 137 tür içerisinde yer almaktadır. Bu türler; Allium peroninianum, Allium rhodopeum, Centaurea consanguinea, Centaurea hermannii, Centaurea kilaea, Dianthus cibrarius, Erysimum aznavourii, Erysimum degenianum, Erysimum sorgerae, Thymus aznavouri dir (Şekil 6.). Bu sayı, İstanbul'daki endemik bitki türlerinin yaklaşık \%16'sının, tozlaşma bahçelerinde kullanım potansiyelinin olduğunu göstermektedir.
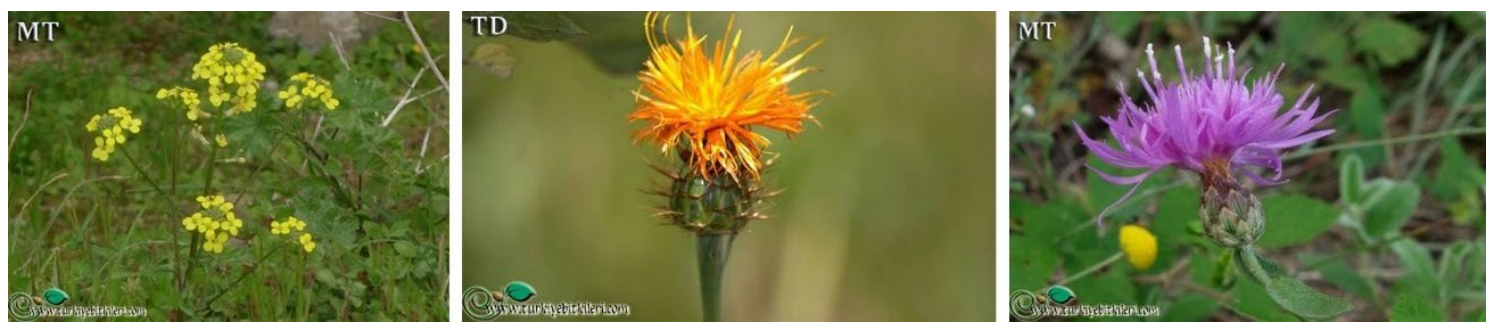

Şekil 6. İstanbul'da doğal olarak yetişen ve tozlaşma bahçelerinde kullanım potansiyeli olan endemik (soldan sağa) Erysimum aznavourii, Centaurea hermannii, Centaurea kilaea türlerine ait fotoğraflar (Url-10, 2017)

Listede, Compositae familyasında 6 cine ait 31 tür, Lamiaceae familyasında 4 cinse ait 18 tür, Rosaceae familyalarında 4 cinse ait 12 tür, Caprifoliaceae familyasında 3 cinse ait 7 tür, Brassicaceae familyasında 2 cinse ait 8 tür, Amaryllidaeceae familyasında tek cinse ait 25 tür, Geraniaceae familyasında tek cinse ait 13 tür, Caryophyllaceae familyasında tek cinse ait 10 tür, Salicaceae familyasında tek cinse ait 5 tür, Boraginaceae ve Crassulaceae familyalarında tek cinse ait 3 tür, Araliaceae ve Primulaceae familyalarında ise tek cinse ait tek tür bulunmaktadır (Şekil 7.).

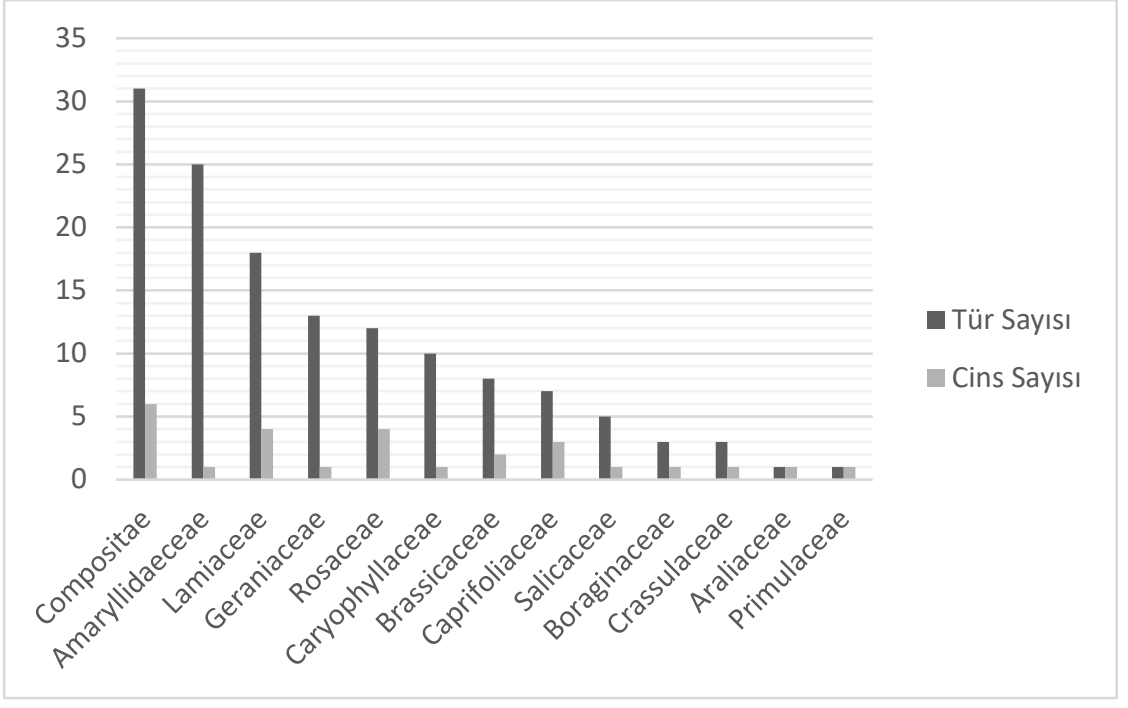

Şekil 7. Familyalara ait cins ve tür sayıları

Compositae familyası 31 tür, Amaryllidaeceae familyası 25 tür, Lamiaceae familyası ise 18 tür ile en çok türe sahip olan familyalardır.

Araştırma sonucunda tespit edilen, İstanbul'da doğal olarak yetişen ve tozlaşma bahçelerinde kullanım potansiyeli olan bazı bitki türleri ve habitat özelliklerine Tablo 1.'de sadeleştirilerek 
yer verilmiştir. Bu tablonun hazırlanmasında, Türkiye Bitkileri Listesi: Damarlı Bitkiler Kitabı (Güner, ve diğ., 2012) ile "Türkiye Bitkileri Veri Servisi" (Url-2) ve "The Plant List" (Url-11) internet sitelerinden yararlanılmıştır.

Tablo 1. İstanbul'da Tozlaşma Bahçelerinde Kullanım Potansiyeli Olan Bazı Doğal Bitki Türleri Ve Habitat Özellikleri (Özdemir, 2017)

\section{TÜR ADI}

Achillea crithmifolia

Achillea nobilis subsp. neilreichii

Allium amethystinum

Allium flavum subsp. tauricum

Allium nigrum

\begin{tabular}{l}
\hline Amelanchier ovalis \\
\hline Aster squamatus \\
Aster tripolium \\
\hline Centaurea diffusa \\
\hline Centaurea solstitialis \\
\hline Centaurea virgata \\
Crataegus monogyna
\end{tabular}

Crataegus pentagyna

Dianthus armeria

Dianthus giganteus

Dianthus leptopetalus

Dipsacus follonum

Dipsacus laciniatus

Echinops microcephalus

Echinops ritro

Erysimum $\times$ cheiri

Erysimum smyrnaeum

Eupatorium cannabinum

Geranium asphodeloides

Geranium purpureum

Geranium sanguineum

Hedera helix

Heliotropium hirsutissimum

Heliotropium supinum

Iberis odorata

Lavandula pedunculata

Lonicera caprifolium

Lonicera etrusca

Malus sylvestris

Mentha aquatica

Mentha pulegium

Origanum vulgare

Primula vulgaris

Rubus canescens

Rubus idaeus

Salix $\times$ fragilis

Salix viminalis

Scabiosa argentea

Scabiosa atropurpurea

Sedum grisebachii

\section{HABITTAT}

Orman, çalılık, çayırlık, tarla

Orman, step, kayalık volkanik yamaçlar, çayırlık, nadas tarla

Pinus ormanları, poterium makileri, gölgeli tepeler, kalkerli kayalık yamaçlar, kırlar

Pinus brutia, Juniperus, Cedrus ve Abies ormanları, frıgana, sazlı toprak, kuru taşlıklar

Kayalı yamaçlar, kırlar, çimenlik yerler, kumlu deniz kenarları

Kayalık yerler, çalılıklar

Deniz kenarı

Kumul deniz kıyısı ve tuzlu deniz bataklığı

Tepeler, yol kenarı, boş alan, tarla

Pinus ormanı, kurak yamaç, nadas tarla, boş alan

Kurak tepeler, step, kurak boş alan

Tepe kenarları, maki, meşe çalıları, karışık ormanlar, yol kenarları

Ormanlık yerler

Açık tarlalar, orman kenarları, yol kenarları

Kayalar, tarlalar, aşınmış kıyılar, meşe çalılıkları

Çağıllık ve sedir çalıları içinde

Nehir kenarları, çayırlıklar, otlaklar

Yol kenarları, kıyılar, tarlalar

Garik, kurak yamaç, tarla kenarı

Stepte kayalık yamaç, garik, nehir yatakları, nadas tarla

Kayalık yamaç, duvar

Kayalık yamaç, ekili alan

Kaya araları, nemli alanlar

Ormanlar, çalılar, çayırlıklar, kıyılar

Kayalık veya gölgelik yerler, çağıllıklar, kıyılar, tarlalar

Koruluklar, çalılar, kayalık yerer

Orman, sulak alanlar, orman kenarları, yol kenarları

Tarlalar ve tarla kenarları, çorak yerler, çakıllı kenarlar

Tarla kenarları

Kayalık yamaç, tarla kenarı

Pinus brutia orman açıklığı, maki, firigana, kireçtaşı ve granit yamaçlar

Orman, çayırlıklar

Çağıllık, uçurumlar, yol kenarları, ekseriya çalılık

Ormanlar, karışık çalılar, kayalık yamaçlar, dereler, arazi kenarları

Dere ve göl kenarları, kıyılar ve bataklıklar

Yazın kuruyan ıslak yerler

Kuru tepe ve kaya yamaçları, kalkerli ve kalkersiz toprak, konifer veya karışık ormanlar, maki

Sık sık makilerdeki yaş yerler, meşe korulukları, çalılık yamaçlar, fındık ağaçlıkları

Seyrek ormanlar, çalılıklar, taşlı tepe etekleri, kıyılar

Ormanlar, çayır kenarları, taşlık yamaçlar

Akarsu ve tarla kenarlarına ekili

Akarsu kenarı

Kıraç yerler, tarlalar, step, taşlı yamaçlar

Yol kenarları, kuru tarlalar, kumullar

Açık veya ormanlık yerler 


\begin{tabular}{ll}
\hline Sedum pallidum & Yaprak döken ormanlar, ana kayalar \\
\hline Solidago virgaurea & $\begin{array}{l}\text { Nehir kenarı ve kireçtaşı kayalık, çoğu kez koruluk, } \\
\text { nadiren ekilmiş topraklar }\end{array}$ \\
\hline Thymus longicaulis & Seyrek koruluk, kayalık yamaçlar, kuru otlaklar \\
\hline Thymus sibthorpii & Kuru yamaçlar, seyrek Pinus ormanları \\
\hline Thymus zygioides & $\begin{array}{l}\text { Pinus brutia koruluğundaki kumlu veya kayalık yerler, } \\
\text { seyrek maki }\end{array}$ \\
\hline
\end{tabular}

\section{TARTIŞMA VE SONUÇ}

İstanbul ilindeki hızlı ve plansız yapılaşma, yanlış arazi kullanımları ve özellikle kumul bölgelerdeki madencilik faaliyetleri nedeniyle, pek çok farklı habitat ile birlikte endemik bitki türlerinin habitatları da tehdit altındadır. Tozlaşma bahçelerinde kullanım potansiyeli olan 10 endemik türün ağırlıklı olarak görüldüğü habitatlar; kayalık yerler, meşe ormanları, kumullar, deniz ve göl kenarlarıdır. Bu alanlarda yapılacak düzenlemeler, bu türlerin bozulmuş olan yaşam alanlarının iyileştirilmesine ve türlerin devamlılığına katkı sağlayacak şekilde olmalıdır. Bu bitkilerin varlığını devam ettirebilmesi bu bitkileri tercih eden tozlaştırıcılar açısından da büyük önem taşımaktadır.

Tespit edilen liste incelendiğinde, listede farklı çiçeklenme dönemlerine sahip tek ve/veya çok yıllık olan bitki türleri bulunduğu görülmüştür. Bu bitkiler her bir çiçeklenme döneminde, bahçede çiçek açan bitkiler bulunabilmesini mümkün kılmaktadır. Bu durum, tozlaştırıcılar açısından çeşitlilik oluşturulması yanında, tek yıllık bitkilerle bahçe görselinin dönemsel olarak yenilenebilecek olması açısından da avantajlıdır. Bahçe planlamalarında farklı zaman dilimlerinde çiçek açan bitkilerin kullanılması ile tozlaştırıcıların farklı dönemlerdeki ihtiyaçları karşılanmış olacaktır.

Listedeki bitkilerin çoğu güneşli alan isteğine sahip olmakla birlikte, yarı gölge ve tam gölgeli alanlarda da yetişme gösteren bitki türleri olduğu tespit edilmiştir. Özellikle gölge alan bitkilendirmelerinde tür seçeneklerinin az oluşu, gölge alan isteğine sahip türler ile oluşturulan tozlaşma bahçelerini, bu alanlar için alternatif kılmaktadır. Listede yer alan, Allium amethystinum, Geranium lucidum, Geranium purpureum, Hedera helix ve Rubus ulmifolius gölge alanlardaki düzenlemeler için uygun türlerdir.

Türlere ait toprak isteklerine bakıldığında, pek çok farklı toprak tipinde yetişme gösteren bitki türleri olduğu tespit edilmiştir. Listede, özellikle kumlu veya yoğun killi topraklara uyum sağlamış bitki türleri de olduğu görülmüştür. Kumlu topraklarda yetişme gösteren bitkilere örnek olarak, Aster tripolium, Centaurea kilaea, Centaurea spinosa, Dianthus capitatus, Dianthus cruentus, Salix cinerea, Thymus zygioides, killi topraklarda yetişenlere ise Allium cyrilli, Allium rotundum, Thymus aznavourii verilebilir. Bu bitkiler yoğun kumlu veya killi toprakları tolere edebilmektedir.

Özellikle kentlerde, ağaç dikimlerinin enerji nakil hatları veya toprak derinliği gibi nedenlerle mümkün olmadığı alanlarda, otsu türler veya yer örtücüler ile tozlaşma bahçesi tesisi mümkündür. Bu alanlarda listede bulunan, özellikle düşük toprak derinliğine ihtiyaç duyan, Achillea crithmifolia, Achillea millefolium, Achillea nobilis, Origanum vulgare, Sedum grisebachii, Sedum pallidum, Sedum sediforme gibi türler kullanılabilir. Bu türler, düşük sulama ve bakım isteğine sahiptir ve kısa sürede toprak yüzeyini örtecek şekilde büyüme göstermektedir.

Bitkilere ait habitat özellikleri incelendiğinde, sulak alanlar, kayalık alanlar, yol kenarları, tepeler gibi, farklı yetişme ortamlarına uyum sağlamış türler olduğu görülmüştür. Türlerin bu özellikleri, onları farklı bahçe tiplerindeki bitki kullanımları için uygun kılmaktadır. Bu türlerin farklı peyzaj düzenlemelerindeki kullanımı, planlanan bahçe tipini aynı zamanda potansiyel bir tozlaşma bahçesine dönüştürmektedir.

- Koku bahçelerinde, Dianthus pinifolius, Lavandula angustifolia, Mentha $\times$ piperita Mentha spicata, Origanum vulgare, Thymus longicaulis gibi türler tercih edilebilir.

- Kaya bahçelerinde, Achillea nobilis, Dianthus giganteus, Erysimum smyrnaeum, Geranium columbinum, Geranium purpureum, Lavandula angustifolia, Lavandula pedunculata, Origanum vulgare, Sedum grisebachii, Sedum pallidum, Sedum sediforme, Thymus zygioides gibi kayalık alanlarda yetişme gösteren türler tercih edilebilir.

- Su kenarlarında yapılacak peyzaj düzenlemelerinde (Şekil 8.), Aster squamatus, Aster tripolium, Erysimum aznavourii, Geranium dissectum, Mentha aquatica, 
Mentha spicata, Rubus caesius, Salix amplexicaulis, Salix caprea, Salix $\times$ fragilis, Salix viminalis, Solidago virgaurea gibi sulak habitatlara uyum sağlamış türler tercih edilebilir.

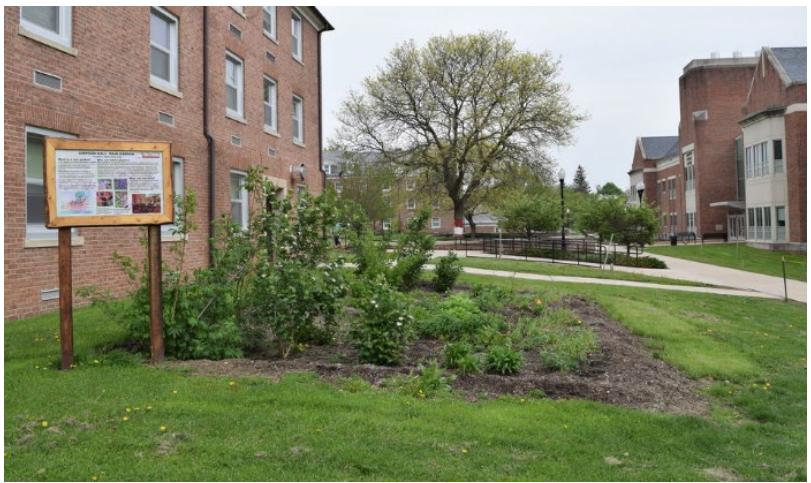

Şekil 8. Simpson Yurdu Tozlaştırıcı Dostu Yağmur Bahçesi (Amerika Birleşik Devletleri) (Urı12, 2017)

- Çatı ve teras bahçelerindeki düzenlemelerde ise (Url-13), Achillea millefolium, Achillea nobilis, Allium neapolitanum, Dianthus giganteus, Geranium sanguineum, Hedera helix, Origanum vulgare, Scabiosa argentea, Sedum grisebachii, Sedum pallidum, Sedum sediforme gibi türlerin tercih edilmesi bahçeyi tozlaştırıcılar açısından zenginleştirecektir.

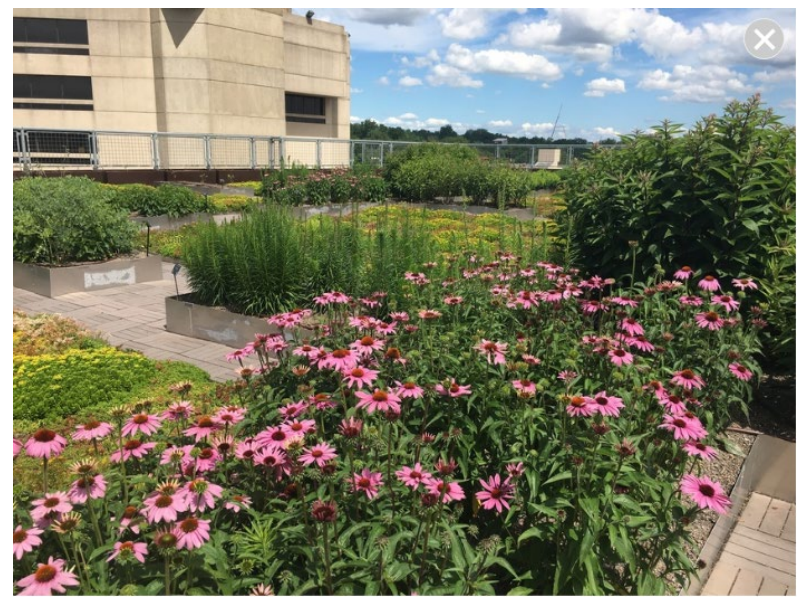

Şekil 9. Çatıda Tozlaşma Bahçesi Örneği (Amerika Birleşik Devletleri) (Url-13, 2017)

Kentsel alanlarda biyoçeşitliği artırmak bu alanlarda yaşayan insanların yaşam kalitesini de artırmaktadır (Savard ve diğ., 2000; Korkmaz, 2016). Tek bir bitkiyle ekilmiş geniş alanlar, tozlaştırıcılar başta olmak üzere böceklere bir mevsimde kısa bir süre geniş besin sağlamaktadır. Diğer zamanlarda ise tozlaştırıcı böcekler için az veya hiç besin sağlamamaktadırlar (Free ve diğ., 1975; Venturini ve diğ., 2015; Korkmaz, 2016). Tozlaşma bahçelerinin, pek çok bahçe tipiyle ilişkili şekilde düzenlenebilecek oluşu, kentsel alanlardaki diğer bahçe tiplerinin de potansiyel tozlaşma bahçelerine dönüşmesine fırsat tanımaktadır. Düzenlenen bahçeler, biyoçeşitliliği destekleyerek, tozlaştırıcıların parçalanmış kentsel habitatlarda yaşamlarını daha kolay devam ettirebilmelerine olanak sağlamaktadır. Bu bahçeler sayesinde, kentin görsel kalitesi artırılarak, kent sakinleri için gözlem ve fotoğrafçılık imkanları oluşturulabilecektir. Tozlaşma bahçeleri ile kentlerdeki tozlaştırıcı nüfusunun dengeleneceği, bu canlılar ile tozlaşan bitkilerin kalitesinde artış gözleneceği, kentte yaşayan insanlar için daha yaşanılabilir ortamlar oluşturulabileceği ve kentlerin ekolojik olarak zenginleştirileceği sonucuna varılmıştır.

\section{KAYNAKÇA}

Bağrıaçık, N. (2017). Polinatör Böcekler ve Küresel Tozlaşma Krizi (Pollinator Insects and

Global Pollination Crisis), Iğdır Üniversitesi Fen Bilimleri Enstitüsü Dergisi, 7(4), 37-41.

Buchmann, S. L., Nabhan, G. P. (1996). Forgotten Pollinators, Washington, D.C.: Island Press 
Cane, J. H., Griswold, T., Parker, F. D. (2007). Substrates and materials used for nesting by North American Osmia bees (Hymenoptera: Apiformes: Megachilidae), Annals of the Entomological Society of America, 100(3), 350- 358. DOI: 10.1603/0013-8746

Ellsworth, D. (2014). Agriculture And Natural Resources Fact Sheet: Attracting Pollinators to the Garden, Ohio State Unıversity Extension, Department of Entomology, 19 Şubat 2018 tarihinde https://u.osu.edu/beelab/files/2015/02/ENT_47_14_jan30-s4vma2.pdf adresinden erişildi.

Evert, R., Eichborn, S. E. (2015). Plant Growth and Reproduction (Part XI). Raven Biology of Plants, (LooseLeaf). 8th Edition. http://www.mhhe.com/biosci/ genbio/raven6b/graphics/raven06b/other/raven06_42.pdf.

Free, J. B., Gennard, D., Stevenson, J. H., Williams, I. H. (1975). Beneficial Insects Present on a Motorway Verge, Biological Conservation, 8, 61-72. DOI: 10.1016/0006-3207

Garbuzov, M. \& Ratnieks, F. L. W. (2014). Listmania: The Strengths and Weaknesses of Lists of Garden Plants to Help Pollinators, 64(11), 1019-1025. DOI: 10.1093/biosci/biu150

Güner, A., Aslan, S., Ekim, T., Vural, M., Babaç, M. T. (2012). Türkiye Bitkileri Listesi: Damarlı Bitkiler, İstanbul: Nezahat Gökyiğit Botanik Bahçesi Yayınları.

Hegland, S. J., Nielsen, A., Lázaro, A., Bjerknes, A. L., Totland, Q. (2009). How Does Climate Warming Affect Plant-Pollinator Interactions, Ecology Letters, 12(2), 184-195. DOI: 10.1111/j.1461-0248.2008.01269.x

Karadağ, A. 2009, Kentsel Ekoloji : Kentsel Çevre Analizlerinde Coğrafi Yaklaşım, Ege Coğrafya Dergisi, 18/(1-2), 31-47.

Korkmaz, A. (2016). Bitkilerde Bal Arısı Polinasyonu, Samsun: Samsun Gıda Tarım ve Hayvancılık İl Müdürlüğü Yayını.

Klein, A. M., Vaissiere, B. E., Cane, J. H., Steffan-Dewenter, I., Cunningham, S. A., Kremen, C., Tscharntke, T. (2007). Importance of Pollinators in Changing Landscapes for World Crops, Proc. R. Soc. B. Biol. Sci., 274, 303-313.

Krischik, V. \& Tenczar, E. (2015). Pollinator Conservation, University of Minnesota, Center for Urban Ecology and Sustainability, https://www.extension.umn.edu/garden/plant-nurseryhealth/docs/2015-pollinator-conservation-bulletin-\%20july.pdf

Mader, E., Shepherd, M., Vaughan, M., Black, S. H., LeBuhn, G. (2011). Attracting Native Pollinators: Protecting North America's Bees and Butterflies, North Adams (MA): Storey Publishing, $371 \mathrm{p}$.

Landis, T. D., Dumroese, R. K., Horning, M. E. (2014). Create a Pollinator Garden at Your Nursery: An Emphasis on Monarch Butterflies, USDA Forest Service, Rocky Mountain Research Station, Forest Nursery Notes, 34(1-2), 4-15.

Özdemir, A. (2017). Kent Ekolojisine Farklı Bir Yaklaşım: Tozlaşma Bahçeleri. (Yayımlanmamış Lisans Tezi). İstanbul Üniversitesi Orman Fakültesi, İstanbul.

Özhatay, N., Koçyiğit, M., Bona, M. (2010). İstanbul'un Ballı Bitkileri, İstanbul: Bal-Der Yayınları.

Potts, S. G., Biesmeijer, J. C., Kremen, C., Neumann, P., Schweiger, O., Kunin, W. E. (2010). Global Pollinator Declines: Trendes, İmpacts and Drivers, Trends in Ecology and Evolution, 25(6), 345-353. DOI: 10.1016/j.tree.2010.01.007

Riepel, J. 2006. Model Projects of Ecological Settlements: Standarts and Criteria. Diploma Thesis, University of Salzburg 'Paris Lodron' (Fachbereich für Geographie, Geologie und Mineralogie), Salzburg.

Savard, J-P. L., Clergeau, P., Mennechez, G. (2000). Biodiversity Concepts and Urban Ecosystems, Landscape and Urban Planning, 48, 131-142. 
Sıralı, R., Cinbirtoğlu, Ş. (2018). Bal Arılarının Tozlaşmadaki ve Bitkisel Üretimdeki Önemi (The Importance of Honey Bees in the Pollination and Plant Production), Arıcılık Araştırma Dergisi, 10(1), 28-33.

Sinnathamby, S., Assefa, Y., Granger, A., Tabor, L., Douglas, K. (2013). Pollinator Decline: US Agro-Socio-Economic Impacts and Responses, Nat Env Sci, 4(1), 1-13.

Şahin, M., Topal, E., Özsoy, N., Altunoğlu, E. (2015). İklim Değişikliğinin Meyvecilik ve Arıcılık Üzerine Etkileri (The Effects of Climate Change on Fruit Growing and Beekeeping), Anadolu Doğa Bilimleri Dergisi, 6(Özel Sayı 2), 147-154.

Tirado, R., Simon, G., Johnston, P. (2013). A Review of Factors that Put Pollinators and Agriculture in Europe at Risk, Greenpeace Research Laboratories Technical Report, 44 p.

Url-1, (2016). https://www.gardeningknowhow.com/garden-how-to/beneficial/pollinatorfriendly-plants.htm (accessed in: 15.02.2017), (In English).

Url-2, (2017). http://www.tubives.com/, (accessed in: 12.01.2017), (In Turkish).

Url-3, (2016). http://www.tarim.com.tr/Ari-ve-Ruzgar,230y, (accessed in: 20.02.2018), (In Turkish).

Url-4, (2017). https://www.plantsmap.com/collections/32022, (accessed in: 20.02.2018), (In English).

Url-5, (2011). http://nurturing-nature.co.uk/gardening-for-wildlife/bumblebee-roundaboutthe-best-ive-seen/ warrington, (accessed in: 10.03.2018), (In English).

Url-6, (2018). https://www.fs.fed.us/wildflowers/pollinators/documents/AttractingPollinatorsEasternUS_ V1.pdf, (accessed in: 20.02.2018), (In English).

Url-7, (2018). https://www.plantsmap.com/organizations/25178/collections/33338, (accessed in: 10.03.2019), (In English).

Url-8, (2018). http://www.helpabee.org/seasonal-bee-gardening.html, (accessed in: 12.01.2019), (In English).

Url-9, (2017). http://istanbulunendemikbitkileri.blogspot.com.tr/2012/03/istanbulunendemik-bitkileri.html (accessed in: 21.04.2017), (In Turkish).

Url-10, (2017). http://www.turkiyebitkileri.com, (accessed in: 21.04.2017), (In Turkish).

Url-11, (2018). The Plant List, www.theplantlist.org/, (accessed in: 10.04.2018), (In English).

Url-12, (2017). https://www.plantsmap.com/organizations/24928/collections/31519, (accessed in: 10.04.2018), (In English).

Url-13, (2017). https://www.plantsmap.com/organizations/23608/collections/31845, (accessed in: 10.04.2018), (In English).

Vanbergen, A.J. and the Insect Pollination Initiative. (2013). Threats to an Ecosystem Service: Pressures on Pollinators, Front Ecol Environ, 11(5), 251-259. DOI: 10.1890/120126

Venturini, E. M., Drummond, F. A., Hoshide, A. K., Stack, L. B., Dibble, A. (2015). Enhancing Wild Bees Guidelines for Providing Native Bee Habitat on Farms, The Xerces Society for Invertebrate Conservation.

Yılmaz, K. (2016). Bal Arılarının Bitkisel Üretimdeki Önemi, Ordu'da Tarım, 118, 1-2.

\section{EXTENDED ABSTRACT}

Preserving and maintaining ecosystem balance depends on maintaining the relationship between plants and the pollinator insects that provide plants with pollination. The products formed through pollination by insects, mainly bees, constitute approximately $35 \%$ of human food. Besides, the production of seeds that will enable the transfer of genes to the next 
generations depends on the work of pollinators. However, there is a decrease in the pollinator population every day due to climate change, habitat losses, use of insecticides and improper land use.

The study was carried out in the metropolitan area of Istanbul, a population of approximately 15 million which has experienced intense urban development and transformation in the last few decades. The first step was a review of the literature relating to the subject and we presented a set of principles requiring consideration in pollinator gardens. Second, we try to list on a genus basis the plants that can be used in the applications of those principles, in order to increase the population of pollinators. To that end, we use the list found in Garbuzov and Ratnieks's 'The Strengths and Weaknesses of Lists of Garden Plants to Help Pollinators' (2014) as a reference. We then use Turkey Plants Data Service (URL-1) to establish a new list, covering the genes that grow naturally in the conditions of İstanbul and the species belonging to those genes

As a result of literature review, we conclude that enforcing the following recommendations may increase the pollination potential of landscape applications in urban areas:

- Assigning specific, differentiated areas to the installation of pollinator gardens,

- Selecting species that bloom in different colors and shapes at different times of the year,

- Protecting the natural and artificial water resources, establishing new ones where there are none,

- $\quad$ Reducing or preventing the use of insecticides.

On the list of plants that grow naturally in Istanbul conditions and have a pollination potential are to be found :

31 species belonging to 6 genera of Compositae family,

18 species belonging to 4 genera of Lamiaceae family,

12 species belonging to 4 genera of Rosaceae family,

7 species belonging to 3 genera of Caprifoliaceae family,

8 species belonging to 2 genera of Brassicaceae family,

25 species belonging to one genus of Amaryllidaeceae family,

13 species belonging to one genus of Geraniaceae family,

10 species belonging to one genus of Caryophyllaceae family,

5 species belonging to one genus of Salicaceae family,

3 species belonging to one genus of Boraginaceae and Crassulaceae families,

and 1 species belonging to one genus of Araliaceae and Primulaceae families.

Urban landscaping arrangements should provide for and facilitate the pollinators continuing their lives in disintegrated urban habitats through applications that increase the richness of natural and endemic species (such as fragrance garden, rock garden, water garden, roof and terrace garden). 